\title{
Chemokines are important cytokines in the pathogenesis of interstitial lung disease
}

\author{
M.P. Keane, T.J. Standiford, R.M. Strieter
}

Interstitial lung disease (ILD) is characterized by alveolar and interstitial inflammation, followed by the progressive derangement of alveolar architecture and deposition of extracellular matrix components. The disease is initiated by an unknown alveolar insult, which is followed by the influx of inflammatory cells to the lung. This recruitment phase results in a several fold increase in all cell types within the airspace, including neutrophils, eosinophils, lymphocytes and macrophages. In addition, substantial interstitial inflammation is apparent, consisting predominantly of newly recruited monocytes and lymphocytes. Alveolar and interstitial inflammation is followed by the loss of type I epithelial cells and endothelial cells, proliferation of type II cells, and expansion of the pulmonary interstitium via the proliferation of fibroblasts and deposition of collagen and other extracellular matrix components [1, 2].

Alveolar and interstitial inflammation in ILD is essential to the development of lung injury and subsequent fibrosis. Neutrophils and neutrophil products have been identified in increased amounts in the airspace of patients with ILD and in animal models of lung fibrosis [3]. These cells induce parenchymal injury by producing toxic radical oxygen species, and by secreting a variety of proteolytic enzymes, including elastase, collagenase, and other neutral proteases. Recruited monocytes contribute to pulmonary inflammation by elaboration of oxygen radical species, proteolytic enzymes, and factors that attract additional inflammatory cells. T-cells and B-cells, like monocytes, are present in increased numbers in the lung interstitium in ILD [4], and the recruitment of lymphocytes to the lung has been shown to precede the development of pulmonary fibrosis in models of lung fibrosis [5]. Furthermore, the development of pulmonary fibrosis in mice can be attenuated or completely abrogated by the selective depletion of CD4+ T-cells, CD8+ T-cells, or both [6]. Activated Tcells produce a number of cytokines that can modulate lung inflammation and fibrosis, including interleukin (IL)-2, IL-4, interferon-gamma (IFN- $\gamma$ ), and chemotactic factors both for leucocytes and fibroblasts. B-cells also contribute to the development of cellular activation and fibrosis in ILD via the overzealous secretion of immunoglobulin, leading to immune complex formation and deposition.

The immunopathological expression of ILD involves complex and dynamic interplay between immune effector

Correspondence: R.M. Strieter, Dept of Internal Medicine, Division of Pulmonary and Critical Care, Box 0360, University of Michigan Medical Center, 3916 Taubman Drive, Ann Arbor, MI 48109-0360, USA. cells, including neutrophils, macrophages and lymphocytes, and cellular constituents of the alveolar-capillary membrane, most importantly lung fibroblasts. The interaction of these lung cells and the mediators that they produce culminates in parenchymal cell injury, collagen deposition, and, ultimately, end-stage fibrosis. While insults that trigger the development of various forms of ILD differ, cellular mechanisms by which inflammatory leucocytes are recruited to the lung in ILD have not been fully characterized. A number of factors that possess leucocyte chemotactic activity have been identified in the lung of patients with ILD, including platelet-derived growth factor (PDGF) [7, 8], fibronectin [9], and transforming growth factor-beta (TGF- $\beta$ ) [10]. The alveolar macrophage is almost certainly involved in recruitment of inflammatory cells, as this cell produces a variety of specific and nonspecific leucocyte chemoattractants. Alveolar macrophages isolated from patients with ILD have been shown to spontaneously express several leucocyte chemotactic factors, including complement factor $5 \mathrm{a}(\mathrm{C} 5 \mathrm{a})$ and leukotriene $\mathrm{B}_{4}\left(\mathrm{LTB}_{4}\right)$. In addition, interstitial and alveolar macrophages from patients with ILD constitutively express macrophage inflammatory protein-1alpha (MIP-1 $\alpha$ ) and monocyte chemoattractant protein-1 (MCP-1), and cells other than lung macrophages contribute to the production of these leucocyte chemotaxins [11-13]. The latter leucocyte chemoattractants belong to the supergene families of chemotactic and activating cytokines, which include CXC, CC and C chemokines [14-28]. These chemokines may be critically involved in the migration and activation of leucocytes in ILD.

The human CXC, CC and C chemokine families of chemotactic cytokines are three closely related polypeptide families that behave, in general, as potent chemotactic factors either for neutrophils, mononuclear cells or lymphocytes, respectively [14-28]. These cytokines, in their monomeric form, range from 7 to $10 \mathrm{kDa}$ and are characteristically basic heparin-binding proteins. The chemokines display highly conserved cysteine amino acid residues: the CXC chemokine family has the first two $\mathrm{NH}_{2}$-terminal cysteines separated by one nonconserved amino acid residue, the CXC cysteine motif; the $\mathrm{CC}$ chemokine family has the first two $\mathrm{NH}_{2}$-terminal cysteines in juxtaposition, the $\mathrm{CC}$ cysteine motif; and the $\mathrm{C}$ chemokine has one lone $\mathrm{NH}_{2}$-terminal cysteine amino acid, the $\mathrm{C}$ cysteine motif (table 1). CXC chemokines are clustered on human chromosome 4, and exhibit 20-50\% homology at the amino acid level. CC chemokines are clustered on human chromosome 17, and exhibit $28-45 \%$ homology at the amino acid level. The one 
Table 1. - The CXC, CC and C chemokine families of chemotactic cytokines

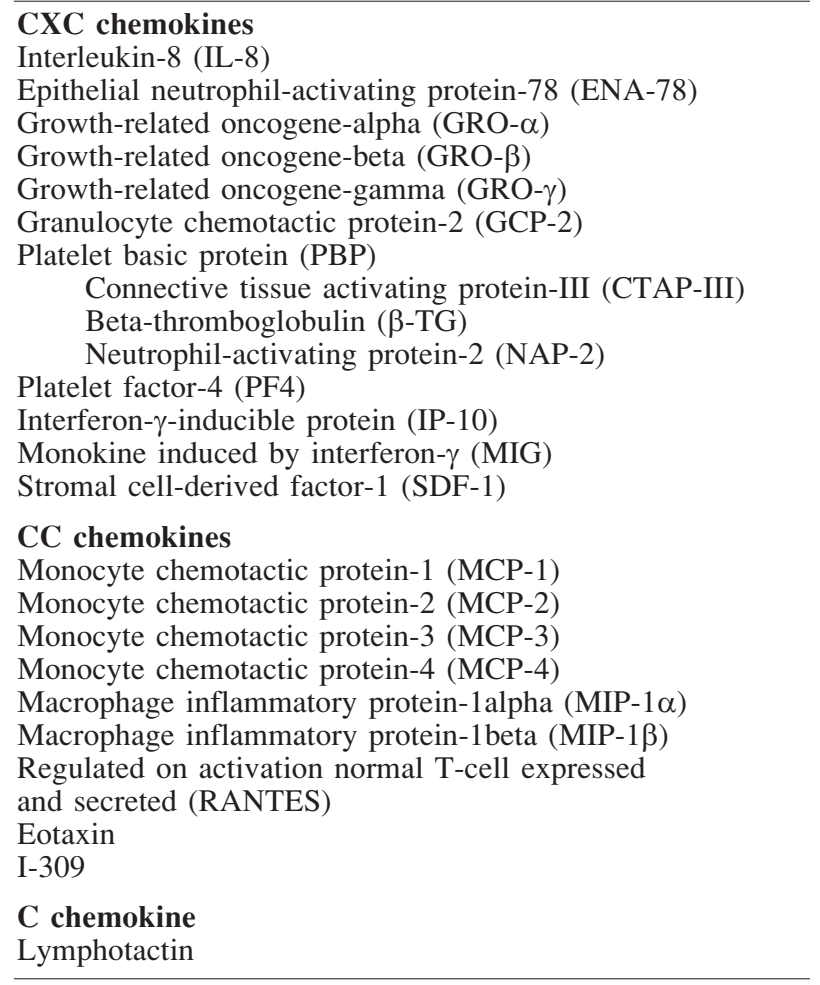

C chemokine, lymphotactin, is located on human chromosome 1 [14-28]. There is approximately 20-40\% homology between the members of the three chemokine families [14-28]. For the purpose of this discussion, we will focus on the $\mathrm{CC}$ chemokines.

The genes for $\mathrm{CC}$ chemokines are clustered on human chromosome 17 (q11.2-q12) [14-28]. In general, the CC chemokine genes have three exons and two introns. The first and second introns of all the genes of this chemokine family are highly conserved [14-28]. The first, second and third exons of these genes encode the 5'-UTR and the signal peptide sequence, the $\mathrm{NH}_{2}$-terminal half of the peptide, and the $\mathrm{COOH}$-terminal half of the peptide and the 3'UTR, respectively [14-28]. The splice junctions between the second and third exons in all CC chemokine genes occur at precisely the same position [21], suggesting that the CXC and CC chemokine superfamily may have diverged from a common ancestral gene [14-28]. The 5'-flanking region of CC chemokines, with the exception of I-309, contain the usual "CCAAT" and "TATA" box-like structures [29, 30]. The 5'-flanking regions of $\mathrm{CC}$ chemokines contains a number of potential binding sites for several nuclear factors, such as NF- $\kappa \mathrm{B}$ and NF-IL-6/C/EBP $\beta$ [29, 30]. In addition, the regulated on activation normal $\mathrm{T}$-cell expressed and secreted (RANTES) promotor contains a transcriptional element similar to IL-2, that may be important for signalling through the cell surface accessory molecule, CD28 on T-cells [29].

The CC chemokine family genes encode complementary deoxyribonucleic acids (cDNAs) that are characterized by a short 5'-UTR, an ORF that encodes both the mature polypeptide and the amino terminal signal sequence, and a long 3'-UTR that contains variable num- bers of "AUUUA" motifs [14-28]. The CC chemokines have been found to be produced by an array of cells, including monocytes, alveolar macrophages, neutrophils, platelets, eosinophils, mast cells, T-cells, B-cells, natural killer (NK) cells, keratinocytes, mesangial cells, epithelial cells, hepatocytes, fibroblasts, smooth muscle cells, mesothelial cells and endothelial cells [14-28]. These cells can produce $\mathrm{CC}$ chemokines in response to a variety of factors, including viruses, bacterial products, IL1 , tumour necrosis factor (TNF), C5a, $\mathrm{LTB}_{4}$ and IFNs [14-28]. The production of CC chemokines both by immune and nonimmune cells supports the contention that these cytokines may play a pivotal role in orchestrating chronic inflammation in the lung during the pathogenesis of ILD.

In this issue of the Journal, PETREK et al. [31] provide evidence that the CC chemokine, RANTES, is present in bronchoalveolar lavage (BAL) cells from patients with sarcoidosis, cryptogenic fibrosing alveolitis (CFA), and fibrosing alveolitis associated with systemic sclerosis (FASSc). The expression of RANTES was determined by immunohistochemistry of protein, reverse transcriptase polymerase chain reaction (RT-PCR) and in situ hybridization of messenger ribonucleic acid (mRNA) from the BAL cells of the subjects. RANTES protein was found to be immunolocalized to $23.5,12.5$ and $7 \%$ of sarcoidosis, FA (combined CFA and FASSc groups), and control BAL cells, respectively. However, the percentages of immunopositive RANTES in BAL cells from control and FA groups were not statistically significant. In the sarcoidosis group, the alveolar macrophage appeared to be the major cellular source of RANTES. In contrast, in the FA group, both alveolar macrophages and eosinophils were found to be cellular sources of this chemokine. In the control group, the alveolar macrophage was found to be the only cellular source of RANTES. Interestingly, T-cells were not found to significantly express RANTES. The protein results for RANTES from the three groups were paralleled by the presence of mRNA, as determined either by RT-PCR or in situ hybridization. In subsequent studies, these investigators correlated the presence of RANTES mRNA to the presence of total and CD45RO+ (memory) subpopulations of T-cells, and found a positive correlation of total and $\mathrm{CD} 45 \mathrm{RO}+\mathrm{T}$-cells in the BALs that contained more than $13 \%$ lymphocytes. However, only a minor proportion of the total T-cells were CD45RA+ (naive). No correlation was found for the presence of neutrophils or eosinophils with the expression of RANTES mRNA in the BAL cells from these groups. While this study was limited to qualitative and nonfunctional analysis of RANTES from BAL, taken collectively, these results suggest that RANTES expression in sarcoidosis, as compared to the groups with FA or controls, may be associated with the accumulation of total and CD45RO+ $\mathrm{T}$-cells in the bronchoalveolar compartment.

RANTES is a CC chemokine that was initially cloned from T-cells by subtractive hybridization, and was thought to be a T-cell specific sequence [32]. Recently, a number of cells have been found to express RANTES, including platelets, monocytes, B-cells, NK cells, epithelial cells, fibroblasts and endothelial cells [23]. While initially described to have selective ability to induce chemotaxis of monocytes and memory CD45RO+ T-cells [33], TAUB 
et al. [34] have demonstrated that RANTES is not selective for CD45RO+ T-cells, and can induce chemotaxis of both CD45RO+ and CD45RA+ T-cells in vitro. Moreover, a number of studies have clearly demonstrated that RANTES is not a selective chemoattractant for T-cells, and that it has the ability in vitro to induce the chemotaxis of other leucocytes, including basophils, eosinophils, mast cells, dendritic cells, monocytes and B-cells [23].

Moreover, RANTES is not the only CC chemokine with the ability to recruit T-cells; the majority of CC chemokines have the ability to recruit these cells, including MCP-1 to MCP-4, MIP-1 $\alpha$, MIP-1 $\beta$ and I-309 [23]. While RANTES can induce migration of eosinophils, other CC chemokines have been found to be chemoattractants for eosinophils, including eotaxin, MIP-1 $\alpha$, MCP-3 and MCP-4 [23, 35]. This suggests a tremendous redundancy in the ability of $\mathrm{CC}$ chemokines to induce chemotaxis of T-cells or eosinophils. Furthermore, the discovery of at least five different $\mathrm{CC}$ chemokine receptors (CCR1-CCR5) [35], of which RANTES may potentially interact with four [35], suggests that the redundancy of $\mathrm{CC}$ chemokine-induced chemotaxis is now more complex; depending not only on the production of the ligand, but also on the pattern of expression and cellular sources of specific CCRs.

Thus, the study by PetreK et al. [31] provides additional important information on the role of chemokines in the recruitment of leucocytes in ILD, and underlines the need to further understand the biology of these cytokines and their receptors in models of pulmonary fibrosis. This strategy can then be used for translational and interventional approaches, to alter the pathogenesis of these often lethal pulmonary diseases.

\section{References}

1. Crystal RG, Bitterman PB, Rennard SI, Hance AJ, Keogh BA. Interstitial lung diseases of unknown cause: disorders characterized by chronic inflammation of the lower respiratory tract. $N$ Engl J Med 1984; 310: 235-244.

2. Panos RJ, King TE Jr. Idiopathic pulmonary fibrosis. In: Lynch JP III, DeRemee RA, eds. Immunologically Mediated Pulmonary Diseases. Pennsylvania, Lippincott, 1991; pp. 1-39.

3. Gadek JE, Kelman JA, Fells G, et al. Collagenase in the lower respiratory tract of patients with idiopathic pulmonary fibrosis. N Engl J Med 1979; 301: 737-742.

4. Davis GS, Brody AR, Craighead JE. Analysis of airspace and interstitial mononuclear cell populations in human diffuse interstitial lung disease. Am Rev Respir Dis 1978; 118: 7-15.

5. Kumar RK. Quantitative immunohistologic assessment of lymphocyte populations in the pulmonary inflammatory response to intratracheal silica. Am J Pathol 1989; 135: 605-614.

6. Piquet PF, Collart MA, Grau GE, Kapanci Y, Vassalli $\mathrm{P}$. Tumor necrosis factor/cachectin plays a key role in bleomycin-induced pneumopathy and fibrosis. $J$ Exp Med 1989; 170: 655-663.

7. Martinet YW, Rom N, Grotendorst GR, Martin GR, Crystal RG. Exaggerated spontaneous exaggerated release of platelet-derived growth factor by alveolar macrophages of patients with idiopathic pulmonary fibrosis. $N$ Engl J Med 1987; 202: 202-209.
8. Mornex JF, Martinet Y, Yamauchi K, et al. Spontaneous expression of the $c$-sis gene and release of a plateletderived growth factor-like molecule by human alveolar macrophages. J Clin Invest 1986; 78: 61-66.

9. Rennard SI, Hunninghake GW, Bitterman PB, Crystal RG. Production of fibronectin by the human alveolar macrophage: mechanism for the recruitment of fibroblasts to sites of tissue injury in interstitial lung diseases. Proc Natl Acad Sci USA 1981; 78: 7147-7151.

10. Broekelmann TJ, Limper AH, Colby TV, McDonald JA. Transforming growth factor- $\beta 1$ is present at sites of extracellular matrix gene expression in human pulmonary fibrosis. Proc Natl Acad Sci USA 1991; 88: 6642-6646.

11. Standiford TJ, Rolfe MW, Kunkel SL, et al. Macrophage inflammatory protein-1 $\alpha$ expression in interstitial lung disease. J Immunol 1993; 151: 2852-2863.

12. Standiford T, Rolfe M, Kunkel S, et al. Altered production and regulation of monocyte chemoattractant protein-1 from pulmonary firoblasts isolated from patients with idiopathic pulmonary fibrosis. Chest 1993; 103: $121 \mathrm{~S}$.

13. Antoniades HN, Neville-Golden J, Galanopoulos T, Kradin RL, Valente AJ, Graves DT. Expression of monocyte chemoattractant protein-1 mRNA in human idiopathic pulmonary fibrosis. Proc Natl Acad Sci 1992; 89: 5371-5375.

14. Baggiolini M, Dewald B, Walz A. Interleukin-8 and related chemotactic cytokines. In: Gallin JI, Goldstein IM, Snyderman R, eds. Inflammation: Basic Principles and Clinical Correlates. New York, Raven Press, 1992; pp. 247-263.

15. Baggiolini M, Walz A, Kunkel SL. Neutrophil-activating peptide-1/interleukin-8, a novel cytokine that activates neutrophils. J Clin Invest 1989; 84: 1045-1049.

16. Matsushima K, Oppenheim JJ. Interleukin-8 and MCAF: novel inflammatory cytokines inducible by IL-1 and TNF. Cytokine 1989; 1: 2-13.

17. Oppenheim JJ, Zachariae OC, Mukaida N, Matsushima $\mathrm{K}$. Properties of the novel proinflammatory supergene "intercrine" cytokine family. Annu Rev Immunol 1991; 9: 617-648.

18. Miller MD, Krangel MS. Biology and biochemistry of the chemokines: a family of chemotactic and inflammatory cytokines. Crit Rev Immunol 1992; 12: 17-46.

19. Baggiolini M, Dewald B, Moser B. Interleukin-8 and related chemotactic cytokines, $\mathrm{CXC}$ and $\mathrm{CC}$ chemokines. Adv Immunol 1994; 55: 97-179.

20. Taub DD, Oppenheim JJ. Chemokines, inflammation and immune system. Therap Immunol 1994; 1: 229-246.

21. Strieter RM, Kunkel SL. Chemokines and the lung. In: Crystal R, West J, Weibel E, Barnes P, eds. Lung: Scientific Foundations. 2nd Edn. New York, Raven Press, 1997; pp. 155-186.

22. Walz A, Kunkel SL, Strieter RM. C-X-C chemokines: an overview. In: Koch AE, Strieter RM, eds. Chemokines in Disease. Austin, TX, R.G. Landes Co., Biomedical Publishers, 1996; pp. 1-26.

23. Taub DD. C-C chemokines: an overview. In: Koch AE, Strieter RM, eds. Chemokines in Disease. Austin, TX, R.G. Landes Co., Biomedical Publishers, 1996; pp. 27-54.

24. Farber JM. HuMIG: a new member of the chemokine family of cytokines. Biochem Biophys Res Commun 1993; 192: 223-230.

25. Proost P, De Wolf-Peeters C, Conings R, Opdenakker G, Billiau A, Van Damme J. Identification of a novel granulocyte chemotactic protein (GCP-2) from human tumor cells: in vitro and in vivo comparison with 
natural forms of GRO $\alpha$, IP-10 and IL-8. J Immunol 1993; 150: $1000-1010$.

26. Walz A, Burgener R, Car B, Baggiolini M, Kunkel SL, Strieter RM. Structure and neutrophil-activating properties of a novel inflammatory peptide (ENA-78) with homology to interleukin-8. J Exp Med 1991; 174: 13551362.

27. Walz A, Baggiolini M. Generation of the neutrophilactivating peptide NAP-2 from platelet basic protein or connective tissue activating peptide III through monocyte proteases. J Exp Med 1990; 171: 449-454.

28. Kennedy J, Kelner GS, Kleyensteuber S, et al. Molecular cloning and functional characterization of human lymphotactin. J Immunol 1995; 155: 203-209.

29. Nelson PJ, Kim HT, Manning WC, Goralski TJ, Krensky AM. Genomic organization and transcriptional regulation of the RANTES chemokine gene. J Immunol 1993; 151: 2601-2612.

30. Miller MD, Wilson SD, Dorf ME, Seuanez HN, O'Brien SJ, Krangel MS. Sequence and chromosomal location of the I-309 gene: relationship to genes encoding a family of inflammatory cytokines. J Immunol 1990; 145: 2737-2744.

31. Petrek M, Pantelidis P, Southcott AM, et al. The source and role of RANTES in interstitial lung disease. Eur Respir J 1997; 10: 1207-1216.

32. Schall TJ, Jongstra J, Dyer BJ, et al. A human T-cellspecific molecule is a member of a new gene family. $J$ Immunol 1988; 141: 1018-1025.

33. Schall TJ, Bacon K, Toy KI, Goedell DV. Selective attraction of monocytes and T-lymphocytes of memory phenotype by the cytokine RANTES. Nature 1990; 347: 669-671.

34. Taub DD, Conlon K, Lloyd AR, Oppenheim JJ, Kelvin DJ. Preferential migration of activated CD4+ and CD8+ T-cells in response to MIP- $1 \alpha$ and MIP-1 $\beta$. Science 1993; 260: 355-358.

35. Premack BA, Schall TJ. Chemokine receptors; gateways to inflammation and infection. Nature Med 1996; 2 : $1174-1178$. 